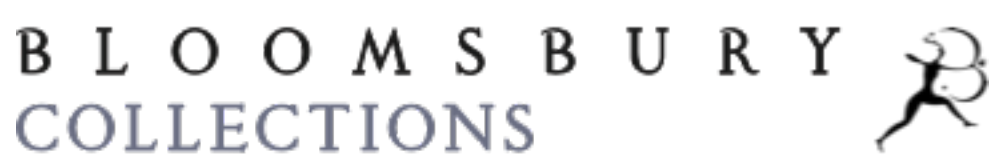

Davala, Sarath, Renana Jhabvala, Soumya Kapoor Mehta, and Guy Standing. "From IIIHealth to Regular Medicine." Basic Income: A Transformative Policy for India. London: Bloomsbury Academic, 2015. 99-114. Bloomsbury Collections. Web. 26 Apr. 2023. <http:// dx.doi.org/10.5040/9781472593061.ch-006>.

Downloaded from Bloomsbury Collections, www.bloomsburycollections.com, 26 April 2023, 14:04 UTC.

Copyright (@) Sarath Davala, Renana Jhabvala, Soumya Kapoor Mehta and Guy Standing 2015. You may share this work for non-commercial purposes only, provided you give attribution to the copyright holder and the publisher, and provide a link to the Creative Commons licence. 


\section{From Ill-Health to Regular Medicine}

\section{Introduction}

Identifying the impact of basic income on health is complex, given that a person's health fluctuates and that it is often difficult to separate out the determinants of particular developments. Some claim that cash transfers do not have much effect on health (Narayanan, 2011). And the well-known economist Amartya Sen has commented, 'When you know that the health system is full of quacks and crooks, cash transfers will be a waste.'

This oversimplifies the situation, and implies that all doctors, nurses and clinics are corrupt or useless, which is surely not the case. It also implies that people cannot not put pressure on medical practitioners to deliver proper care.

Internationally, many studies have shown strong positive effects of cash transfers on child and adult health, incidence and severity of illness, and use and effectiveness of medical services. There is evidence from many Latin American CCT schemes that cash transfers boost use of preventative health services, and lead to people going for more health check-ups (Bastagli, 2009). This was also seen in the Namibian basic income pilot.

The health effects may be four-fold. First, basic income may improve resilience, enabling people to have more resistance to sickness, through better diets, more regular treatment, diminished stress due to economic insecurity, and so on.

Second, it may improve preparedness, the ability to respond in a timely manner to an illness or accident. This may involve hospitalizing the person or incurring needed medical expenses, or going in for preventative practices such as immunizing children and taking out health insurance.

Third, there may be a reduction of debt incurred to fund medical expenses. The basic income may give families the ability to save or pool resources for such expenditure, rather than rely on high-interest debt. 
Fourth, and something that has received less attention, is that besides the effect of cash or income in itself there is a powerful positive effect of income security the assurance of having money - through inducing people to have longer planning horizons, less stress and less anxiety (Marmot and Wilkinson, 1999). For example, in a universal income security scheme in Manitoba, Canada, the community effects improved individual states of mind and healthcare (Forget, 2011).

With those four considerations in mind, this chapter considers the impact basic income can have on health, drawing mainly on the evaluation surveys. But before doing so, it may be useful to review the institutional features of the medical system.

\section{The medical system in rural Madhya Pradesh}

India spends only 1.2 per cent of its GDP on health, compared with 2.7 per cent in China. Other Asian countries that spend proportionately more than India include Indonesia, Malaysia, Nepal, the Philippines and Sri Lanka (Kohler, 2014). Healthcare in India has been dominated by provision of public health services that are in theory universal and subsidized, delivered through a network of Primary Health Centres (PHCs), visiting Auxiliary Nurse Midwives (ANMs) and Accredited Social Health Activists (ASHAs).

This system has concentrated mostly on family planning and maternal and child health, especially child immunization and reducing maternal mortality through monetary incentives for women to opt for institutional delivery. In this regard, data from the project indicated that the public service has been effective and fairly comprehensive, particularly with regard to child immunization.

Alongside the public services, a private system of primary healthcare consists of private doctors, mostly local medical practitioners (LMPs), colloquially called Bengali doctors as many of them are non-locals from West Bengal. They have been living and working in the villages for many years and have been providing a service that seems appreciated by villagers. As one LMP told the research team, referring to one village covered by the pilot:

Many people from Sahavada come to me for treatment. If someone is seriously ill, they come to fetch me. During monsoon months, the only way to go to the village is by boat. I treat mainly seasonal illnesses. For more serious illnesses, I refer them to the hospital in Depalpur, which is 13 kilometres from here, or to Indore, which is 55 kilometres from here. 
Private and government hospitals are mainly in small towns, and are used by villagers not only for serious cases requiring hospitalization, but also for diseases and ailments requiring out-patient treatment. Primary Health Centres are used more as health outposts for first aid and immunization. In general, distance to health outposts was a problem in the pilot villages, particularly in the tribal basic income village. Residents there had to go more than eight kilometres to reach the primary health sub-centre; the nearest government hospital was 23 kilometres away. In the non-tribal villages, the distance to the nearest government hospital was about 17 kilometres.

\section{Basic income and health resilience}

Across India, ill-health and disability associated with deprivation and lack of access to preventative and remedial healthcare are among the most serious social and economic challenges, leading to chronic poverty. The possible impact of basic income on ill-health was among the more sensitive subjects in the project. And perhaps the results were among the most encouraging.

Note that, in general, across all the villages covered by the pilots, there was a greater incidence of what could be called health poverty, in that many of those households who professed to have enough income for food were suffering from ill-health or disability, and lacked easy access to affordable medical attention.

\section{Reducing incidence of illness}

In all villages covered by the pilot, households were asked whether anybody had fallen ill in the previous three months, defined as having had an illness lasting for more than 24 hours and needing treatment, but not hospitalization.

By the time of the FES, after the basic income had been operating for a year, while 64 per cent of households in the control villages reported an episode of illness in the previous three months, only 52 per cent of households in the basic income villages reported an episode of illness (Figure 6.1). And fewer basic income households had more than one person ill. This pattern held for all social and demographic groups, including the elderly (those above the age of 60) and children below the age of 5 , even though both these groups had a relatively higher propensity to fall ill in both types of village (Table 6.1). 
Figure 6.1 General villages: Percentage of households having sick or injured members in past three months, by type of village

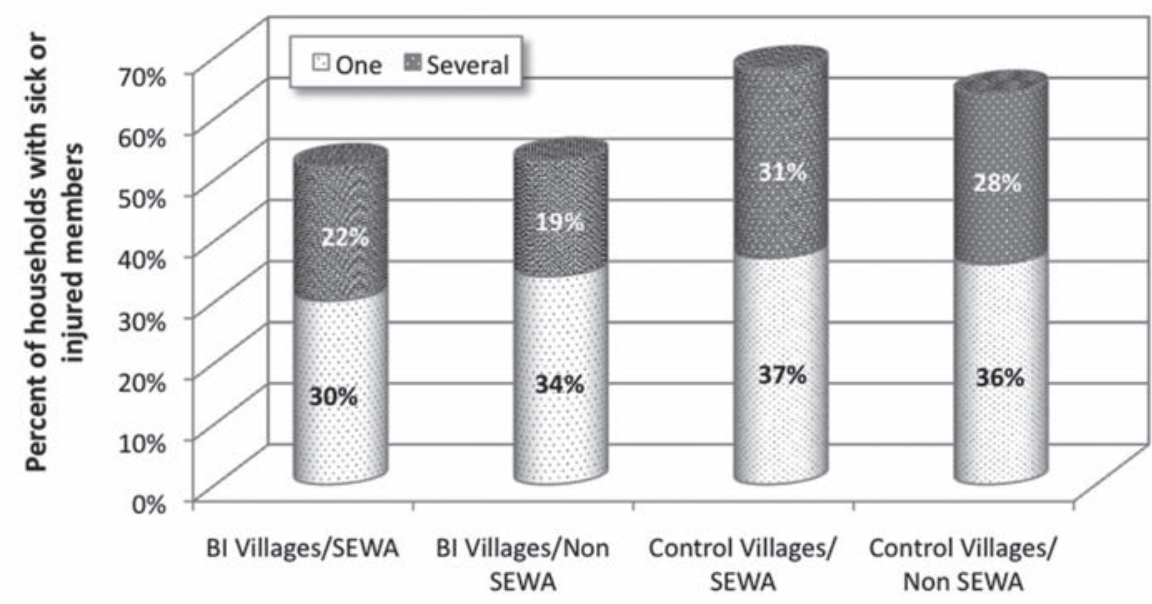

Source: MPUCT FES, 2012; $\mathrm{n}=2034$

Table 6.1 General villages: Percentage of individuals falling ill in past three months, by characteristics and type of village

\begin{tabular}{llllllll}
\hline & Men & Women & $\begin{array}{l}\mathbf{0 - 5} \\
\text { years }\end{array}$ & $\begin{array}{l}\mathbf{6 - 1 7} \\
\text { years }\end{array}$ & $\begin{array}{l}\text { Working age } \\
(\mathbf{1 8 - 5 9} \text { years })\end{array}$ & Elderly & Disabled \\
\hline BI villages & 13.1 & 15.5 & 18.0 & 10.1 & 13.8 & 23.7 & 19.0 \\
$\begin{array}{l}\text { Control } \\
\text { villages }\end{array}$ & 18.5 & 20.0 & 25.1 & 15.3 & 18.5 & 27.9 & 29.0 \\
\hline
\end{tabular}

Source: MPUCT FES, 2012; $\mathrm{n}=1988$

In the tribal village, the basic income also had a salutary effect on health. Whereas 70 per cent of households in the control village reported that at least one person had been ill during the three months before the FES, only about 58 per cent of households in the basic income village had an illness in that period. The effects were even stronger for women, with women in the basic income village reporting a significantly lower likelihood of falling ill, a 15 percentage point difference. In the case of men, there was an 11 percentage point difference.

\section{Improving health}

Resilience to ill-health, or the ability to recover from illness, is influenced by various factors. Food insecurity, defined for practical purposes as having insufficient income for two meals a day, reduces the ability to fight off illness, 
particularly among the ultra-poor. Lack of money can induce people to curtail treatment when they start to feel better. Medical courses of treatment must be completed to be effective. In reducing these insecurities the basic income could be expected to have positive effects.

Even by the time of the Interim Evaluation Survey, the basic income was correlated with an improvement in health, the main reason cited being that households could afford medicines or treatment. This trend persisted to the end of the pilot, by which time a majority of basic income recipients (66 per cent) attributed improvement in health to the enhanced ability to afford medicines and/or treatment (Figure 6.2). Some households (about 27 per cent) also spoke of having food more regularly and how the cash had helped reduce anxiety (16 per cent), leading to the perceived improvement in health.

Similar changes took place in the tribal village. Nearly 22 per cent of households in the basic income village spoke of taking medicines more regularly, whereas only 4 per cent said this in the control village.

In the general villages, scheduled tribe respondents were relatively more inclined to cite more regular food intake as a reason for the improvement. Nearly 37 per cent of tribal basic income recipients spoke of having more food as the most important reason for an improvement in health compared to 27 per cent for all households.

Figure 6.2 General villages: Percentage of basic income households with health improvement, by perceived main reason

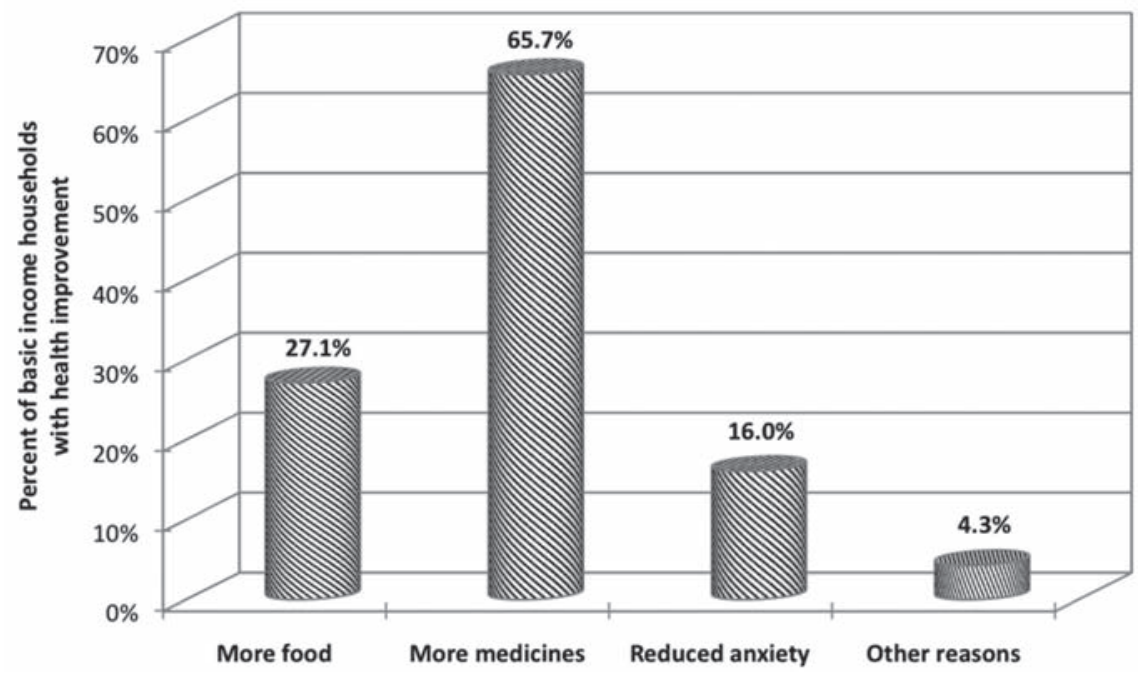

Source: MPUCT FES, 2012; $\mathrm{n}=705$; multiple responses possible 
Irrespective of the channel through which an improvement in health was obtained, over three-quarters of basic income households attributed the improvement partly or fully to the basic income payments. Also, for some reason, more households in SEWA villages spoke of an improvement in their health (81 per cent) compared with those in non-SEWA villages (69 per cent).

Higher food consumption could be a reason. When asked what had led to the improvement in health, 29 per cent of households in SEWA basic income villages said they had been able to afford more food, compared to 24 per cent who said this in non-SEWA villages. Similarly, 17 per cent of households in the SEWA basic income villages reported taking medicines more regularly, compared to 12 per cent in non-SEWA villages.

The combination of women receiving the cash and the presence of SEWA did seem to result in changes in healthcare behaviour. During the course of the pilot, women often expressed concern about their family's health and their own, and many reported that they did not know what to do. Here, SEWA's actions may have made a significant difference.

Women wanted to know how to take care of their health, particularly preventative actions. Many complained about not receiving healthcare to which they were entitled from the government. Some worried whether it was right to spend money on their own healthcare. On all these aspects, during regular visits to the villages, SEWA agewans helped women by providing information on healthcare facilities, guiding them on how to monitor the work of ANMs and ASHAs, and advising them on where to file complaints in case these workers were not performing their duties properly.

The major implication of these findings is that the basic income facilitates a more rational response to illness, largely through acquiring medicines and taking them regularly. A higher intake of food too can explain potential improvements in health status, particularly for tribal households. These are aspects of healthcare that are well known but underappreciated.

\section{The impact on healthcare practices}

When somebody shows signs of having an illness or disease, the first initiative undertaken by the family, if it has the means, is to seek treatment, perhaps taking the person to a hospital. It was hypothesized that the basic income would enable recipients to take such decisions by allowing them to make timely use of local health services. 
Asked what was their initial reaction, the most common practice in the 20 general villages was to go to a private hospital ( 41 per cent), followed by private doctors or local medical practitioners (34 per cent) and then government hospitals (18 per cent). Most hospitals, private and public, have out-patient departments, which are widely used, meaning that about 60 per cent of people go to a hospital of some kind.

The fact is that relatively few went to government hospitals. One may presume that the first and second categories include some who resorted to the so-called Bengali doctors. Only just over 1 per cent said they went to a Primary Health Centre, ANM or ASHA organizer. This is remarkable, as it means that scarcely any households were using a public health facility other than a government hospital as a first point of contact.

Discussions in the villages revealed that public health facilities were used by residents primarily for preventative care, particularly immunization of children. When it came to illnesses that could be addressed through out-patient care, most respondents in both types of village reported using private hospitals, local doctors and government hospitals.

Over the period of the pilot, use of government hospitals as a first port of call declined slightly, from 20 per cent to 18 per cent. More private hospitals and primary doctors were being used at the time we did our final evaluation survey - private hospitals up from 40 per cent to 41 per cent, and primary doctors and local medical practitioners up from 33 per cent to over 34 per cent.

But was the shift from public to private healthcare greater in basic income villages? At the time of the FES, half the households in basic income villages said that their first point of contact was a private hospital, followed by a private doctor or local medical practitioner/chemist/medical shop (35 per cent). Only 12 per cent went to government hospitals.

However, it was not the basic income that had induced them to shift to private care. While there was a shift from government hospitals to private health services in basic income villages - slightly more went to private hospitals than they did a year previously (50 per cent compared to 48 per cent) - it was modest. More households in the basic income villages were already using private health services, and the basic income merely increased an already strong tendency to rely on private healthcare.

By comparison, in the control villages, 33 per cent of households opted for a private hospital as a first point of contact at the time of the FES (up only marginally from 32 per cent) while 41 per cent went to local doctors/chemists/ 
medical shops, the same as 12 months earlier. There was a modest decline in use of government hospitals, from 25 per cent to 23 per cent.

In sum, by the end of the pilot, about 85 per cent of patients were being taken to a private practitioner/doctor/hospital as a first point of contact in basic income villages, compared to 74 per cent in control villages.

The shift was also seen in the Post-Final Evaluation Survey (PFES), the short survey aimed at gathering reflections from respondents in two basic income villages regarding the impact of the benefits on various aspects of their lives. Respondents confirmed the shift to private hospitals, with 36 per cent reporting that they had used more private health services, 50 per cent saying they had made no change, another 12 per cent saying that they had used more of both public and private services, and only 3 per cent saying they had used more government medical services than 12 months before.

In the tribal villages, when people fell ill, their first contact tended to be the local medical practitioner or local chemist, while the second most common was the out-patient department of a hospital. This pattern could have been because there was no PHC in their vicinity. However, by the end of the pilot, while households in the basic income village had shifted their preferences to a private hospital, in the control village there was a shift to home remedies, even though LMPs remained the main first preference.

More significantly, the shift from government hospital was much more pronounced. At the time of the baseline, an almost identical 20 per cent were using a government hospital. By the end of the pilot, only 12.5 per cent were doing so in the basic income village, compared to 18 per cent in the control village.

\section{Hospitalization}

In the general villages, although the rate of hospitalization during the course of the pilot was similar in both types of village, with about 40 per cent of households having at least one person hospitalized, the survey data revealed several patterns.

Although the proportion of men and women in the population was similar, as was their propensity to fall ill, nevertheless by the end of the pilot more women were taken to hospital in the basic income villages (56 per cent) than in the control villages (53 per cent). So, it may have been the case that the individualized basic income improved the chances of women receiving proper treatment in hospital. 
Private hospitals were the first choice for hospitalizing both men and women, a pattern observed in the baseline that had strengthened slightly by the time of the FES. At the time of the baseline, nearly 84 per cent in basic income villages and 81 per cent in control villages reported having used private hospitals when needed; the figures had increased to 86 per cent and 83 per cent respectively by the end of the pilot.

A higher proportion of men were taken to private hospitals in both types of village. Women were twice as likely as men to use government hospitals. No significant differences were observed between women in SEWA and non-SEWA villages. Although the basic income was associated with a higher probability of women being hospitalized, there remained a differentiation in kind of hospital. Women were still taken to government hospitals more often than men.

Nevertheless, here there was a notable change. The probability of women going to a private hospital or clinic was much higher in the basic income villages than in control villages - rising from 77 per cent to 83 per cent whereas the impact for men was less - rising from 88 per cent to 91 per cent. So, if private care was better, the basic income effect was a relative improvement for women.

The evaluation data also indicated that the ill or injured were taken earlier to hospitals in the basic income villages. While 16 per cent of households in the control villages said that they took ill members to the hospital seven days or more after the onset of illness or injury, only 14 per cent delayed that long in the basic income villages.

The basic income, and the savings associated with it, may have enabled families to hospitalize an ill person as soon as a diagnosis was made, rather than delay, leading to someone becoming sicker. This is the sort of effect that can easily be overlooked or underestimated. Treatment delayed can sometimes be treatment too late. And this is another aspect of the emancipatory value of the basic income, since going for treatment earlier almost certainly reduces the eventual total cost.

\section{Healthcare privatization}

A feature of contemporary rural India is the powerful trend to private rather than government health services. This was shown vividly in the pilots. When households received cash, a majority opted for private healthcare, in private hospitals or through treatment by private doctors, LMPs, chemists or medical shops. 
Was this treatment better than the treatment available at government hospitals or PHCs? The survey data available do not enable us to analyse the effectiveness of public services. But the reasons for resort to commercial medical services seemed numerous, including convenience. Many respondents in the case studies expressed broadly similar views. Thus, Kalabai, a 52-year-old agricultural worker and wife of a small-scale farmer and agricultural labourer, commented:

We go to a private doctor regularly because we do not get government doctors on time and they do not cure illness.

Devi Singh, a small-scale Bhil caste farmer, was a typical case of somebody needing long-term medical care:

I have been suffering from asthma for the past four years. I need treatment twice a month, for which I spend 700-800 Rupees. For any illness, we go to a private doctor. The government hospital is far away and does not provide good treatment. So we don't go to government hospitals, and rather visit private doctors. Actually, we spend the cash transfer money mostly on health.

Even Gumaan Singh, the former naukar and agricultural labourer described in Chapter 3, resorted to private care:

There is a government doctor in Bavlia [four kilometres away]. But we generally go to a private one. The government doctor also takes fees, but he does not provide treatment properly.

Reshambai, a landless backward caste householder, was another who had multiple reasons for opting for private care, in spite of the cost:

We go to private doctors because the government doctors are not available all the time, and the treatment is not good. Private doctors are always available. They take 200 Rupees as consultation fee. But the medicine they give works.

Kesar Singh, a 65-year-old Bhil wage labourer, summed up the widespread sense of frustration:

We fall ill a lot during summer. We go to the nearby village for treatment. There is no doctor in our village. There is a private doctor at Jamburi who does not take a fee. He charges only the cost of the medicine. There is a government doctor eight kilometres away from our village but we always go to the private one because the private doctor cures quickly and properly. The government doctor does not listen to us.

In short, many villagers expressed a preference for private doctors, for diverse 
reasons ranging from quality to reliability and proximity, and even cost. Going private therefore was seen as less expensive, because of the cost of obtaining public services.

The evaluation data also suggested that whereas private healthcare was mainly a preserve of the rich before the pilot, it was mostly the poor who shifted. They had been dependent on 'failing public services' and, given the enhanced freedom to choose, decided to emulate, for better or worse, the norm in their community by moving to private doctors, LMPs and private hospitals.

We used four proxies for poverty to test the hypothesis that the shift was by the income poor - literacy of head of household, whether the household owned any land, whether it possessed a BPL or AAY card, and type of roof (pucca or kutcha). Low-income families were identified as those with illiterate heads, no land, a kutcha roof or a BPL/AAY card.

Using the first point of medical contact at the time of the FES and before the pilot started as the variable of interest, we found that the poor as defined by these proxies in basic income villages shifted more to private health services than the rich, who were mostly already relying on them before the start of the pilot.

There was a small percentage increase ( 49 per cent to 52 per cent) in the proportion of households with illiterate heads accessing private hospitals in basic income villages as compared to no increase in control villages. Similarly, the proportion of those using private hospitals increased from 42 per cent to 44 per cent for households with a kutcha roof, from 44 per cent to 46.5 per cent for landless households and from 33 per cent to 35 per cent for BPL households in basic income villages, whereas there was no change in the control villages.

\section{Preventative practices - immunization}

One justification for the basic income being unconditional is the view that there is no need to require recipients to undertake preventative measures because they can work out what is desirable for themselves, as long as facilities are available and people are informed of the advantages of particular practices. This view is supported by foreign evidence. In Brazil, with the mildly conditional Bolsa Familia, it was found that the condition that families had to take designated actions if they wanted the cash had no impact on the frequency of health check-ups or child immunization (Soares et al., 2010).

This implies that people can be relied upon to act rationally. The presumption of rationality can be tested by reviewing the actual incidence of child immunization in the villages. Levels of child immunization were over 90 per cent in the 
20 general villages and the two tribal villages covered for the pilot, except for the MMR (measles, mumps and rubella), where the rate was slightly below 90 per cent. Although the differences were not statistically significant, a slightly higher proportion of children received immunization in basic income villages, with more boys as compared to girls receiving immunization in those villages, whereas slightly more girls received immunization in the control villages. The overall rates were so high that none of those differences could be regarded as significant.

\section{Health insurance}

Although a health incident is a classic shock, as discussed in Chapter 3, and thus can lead to a financial crisis, the classic remedy of health insurance is rare in rural India. Nevertheless, all respondents were asked whether or not they had taken out any health insurance. Very few had; merely 5 per cent in the general villages said they had taken health cover in the six months prior to the FES, mostly from private providers.

However, there was a difference between basic income and control villages. While 8 per cent of basic income recipients said they had taken out health insurance in the period, only 2.5 per cent of control village households had done so. Among those who had done so in basic income villages, nearly three in every four reported that this was due partly or fully to the basic income.

Of course, a more common form of health insurance has been personal savings. As noted in Chapter 3, among those who were saving from their basic income, quite a few reported that they saved in case they suddenly needed money for medical expenses. It was a form of informal health insurance. The liquidity provided cover in case some other contingency became their priority.

\section{Spending and borrowing for healthcare}

The amount of basic income was very modest in comparison to healthcare costs faced by most villagers. Yet one of the most significant findings was that households receiving the basic income were more likely to have increased spending on all aspects of medical care.

Eight months into the pilot, at the time of the Interim Evaluation Survey, the differences were statistically significant for spending on medicine, doctor's treatment and hospital treatment, with households receiving the basic income more likely to have increased spending in each case (Table 6.2). 
Table 6.2 General villages: Percentage of households with increased medical spending, by receipt of basic income

\begin{tabular}{llcl}
\hline \multicolumn{3}{c}{ Receiving basic income } \\
\hline Sphere of spending & Yes & No & Chi-square \\
\hline Medicines & 77.3 & 63.1 & $21.971^{* * *}$ \\
Doctor's fees & 68.4 & 57.4 & $21.683^{\star * *}$ \\
Hospitalization & 65.9 & 53.1 & $15.227^{\star * *}$ \\
\hline
\end{tabular}

Source: MPUCT IES, 2012; $\mathrm{n}=893$

Among those in basic income villages who reported increased spending on doctors and medicines, nearly two-thirds attributed the increase partly or fully to the basic income, with a greater proportion of households in SEWA villages saying they were able to increase their medical spending on account of the basic income (72 per cent) than in non-SEWA villages (60 per cent).

Disaggregating by social groups, it seemed scheduled caste households, particularly in SEWA villages, were the main group benefiting in this respect, significantly increasing their spending, both on medicine and doctors, compared to counterparts in control villages.

However, medical expenses are a major source of debt for poor families, the one most likely to impoverish them. So, it was notable that borrowing for hospital expenses was significantly lower in basic income villages by the end of the pilot, 46 per cent doing so compared to 55 per cent in control villages (Figure 6.3).

More households in basic income villages reported using their own income/ savings to pay for hospitalization. Reliance on own income and savings was slightly higher in SEWA villages receiving the basic income. The case of Jitmal, an elderly person from Jagmalpipliya, describes the shift.

In case of any illness we go to the Kanadiya private hospital where 100 to 200 Rupees are spent on medicine in each visit. Some time back I got sick because of diarrhea. Some 2,000 Rupees were spent on the treatment. I was able to pay the money from the money I had been saving from the basic income. If this money had not been there, I would have had to borrow from people and would have fallen into debt with an interest rate of 3 per cent to 5 per cent.

What was also encouraging was that scheduled caste (SC) and scheduled tribe (ST) households in basic income villages tended to rely less on loans than counterparts in control villages. So while around 64 per cent of SC respondents and 68 per cent of ST respondents in control villages had used loans or had sold/ 
Figure 6.3 General villages: Source of funding for hospitalization, by type of village

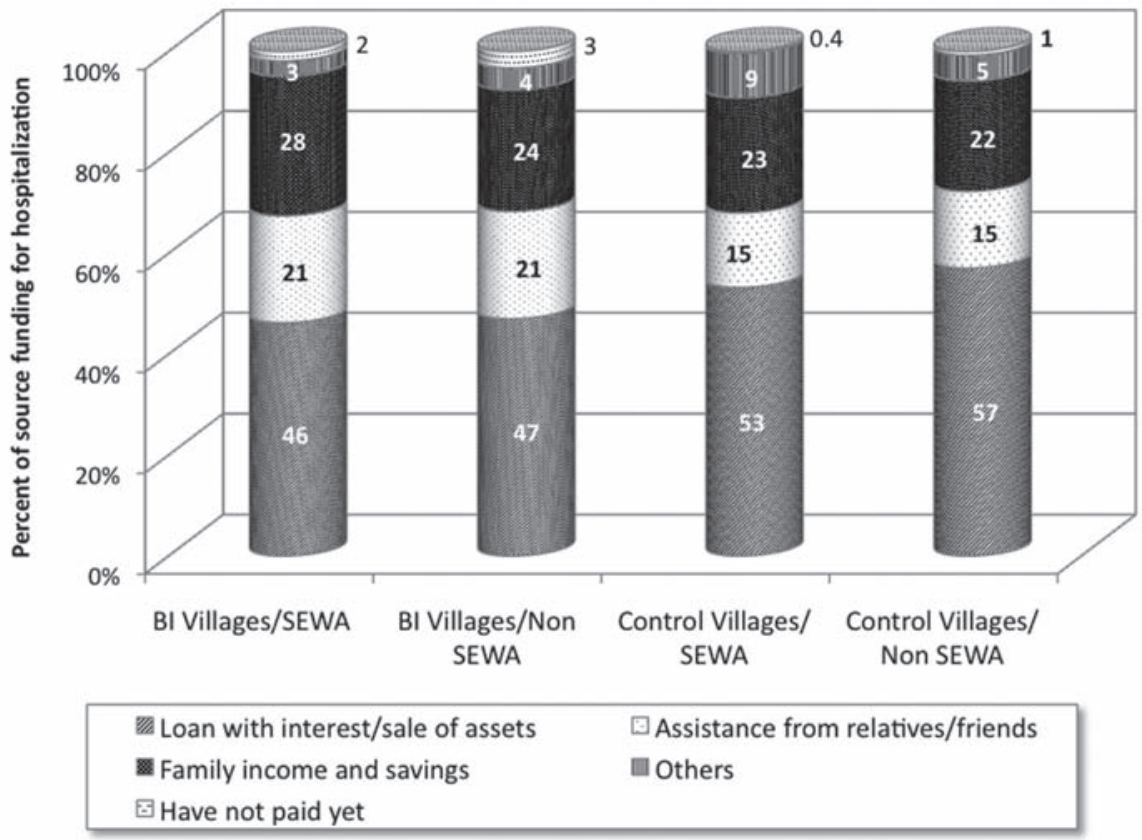

Source: MPUCT FES, 2012; n=954

mortgaged their assets to fund hospitalization expenses, in basic income villages only 52 per cent of SC respondents and 46 per cent of ST respondents did so.

They relied more on their income and savings to fund the expenses, and also spoke of pooling some of their basic income money to finance healthcare for one or more members needing treatment. The testimony of Rajmal, an SC farmer from the village of Gogakhedi, is illustrative of the manner in which such pooling was done:

There are five members in our family who are getting the cash. The elder son's account is separate and his money is not yet withdrawn as he stays away from home. The other four of us get 800 Rupees collectively in a month. I have been saving the last 3-4 months' money. My daughter came home six months back for her first delivery. That took place at Mission Hospital and it cost 12,000 Rupees. We used some of the money to provide my daughter with good food, fruit and health drinks.

A similar pattern was revealed in the tribal village pilot. Only half resorted to loans with interest or asset sales to pay for hospital treatment, compared with 58 
per cent in the control village. Correspondingly more in the basic income village relied on assistance from relatives and friends and their own income and saving.

\section{Conclusions}

The impact of basic income on two groups that have particular problems is considered in a later chapter. Thus far, we can see that it has several effects, some of which are easily overlooked. There seems to have been a generally positive effect on health, reducing the incidence of ill-health. No doubt, a virtuous circle of more and better food, less financial anxiety and more financial liquidity has helped.

The basic income seems also to have facilitated a more rational or considered response to illness, through more regular medication and, for some households, more intake of food.

The basic income gave families more choice in the type and in the timing of healthcare. Clearly, there is an institutional crisis in Indian healthcare, and there is no point in concealing the fact that public healthcare services are inadequate. They may or may not be worse than what people think is on offer by opting for private treatment.

What is clear is that when given the choice, more opt to pay for private services. Perhaps this is a switch from government to private services, perhaps a tendency to opt for treatment rather than forego any. All we can say is that the shift to private healthcare is a reality and that the basic income enabled more families to obtain treatment.

Finally, the basic income seems to have reduced the burden on households to fund their health expenses through a vicious cycle of debt. It seems to have given them an opportunity to pool money to fund health shocks and finance illnesses requiring hospitalization through their own (higher) income and savings. In all these respects, the basic income could be said to have been both emancipatory and developmental. It loosened constraints in one vital sphere of rural life.

\section{Note}

1 Allowance should be made for the possibility that there may be cases of obesity even in conditions of widespread malnourishment. One argument in favour of 
straightforward cash benefits in developed countries is that they would reduce stress among parents and the high incidence of obesity due to improved diets for children. See: 'Low-income moms under stress may over-feed infants'. http://www. eurekalert.org/pub_releases/2012-04/aaop-lmu042312.php; 'Fear of not having enough food may lead to obesity'. http://www.eurekalert.org/pub_releases/2012-04/ aaop-fon042312.php 